\title{
Impaired NO-dependent vasodilation in patients with Type II (non-insulin-dependent) diabetes mellitus is restored by acute administration of folate
}

\author{
R. W. van Etten ${ }^{1,2}$, E. J. P. de Koning ${ }^{1}$, M. C. Verhaar $^{1}$, C. A. J. M. Gaillard ${ }^{1,2}$, T. J. Rabelink ${ }^{1}$ \\ ${ }^{1}$ Department of Vascular Medicine and Diabetes, University Medical Center, Utrecht, The Netherlands \\ 2 Department of Internal Medicine, Eemland Hospital, Amersfoort, The Netherlands
}

\section{Abstract}

Aims/hypothesis. Patients with diabetes are characterised by endothelial dysfunction and cardiovascular mortality. In particular endothelium-derived nitric oxide has emerged as a first line mechanism against atherosclerosis. Hyperglycaemia causes oxygen radical stress but has also been associated with endothelial nitric oxide synthase uncoupling, both lead to decreased nitric oxide-availability. We recently showed that folate reverses eNOS uncoupling in vitro. Therefore we hypothesise that folate improves endothelial function in Type II (non-insulin-dependent) diabetes mellitus in vivo.

Methods. Using forearm plethysmography, we evaluated the effect of local, intra-arterial administration of 5-methyltetrahydrofolate (5-MTHF, the active form of folic acid, $1 \mu \mathrm{g} / 100 \mathrm{ml} \mathrm{FAV} / \mathrm{min}$ ) on forearm blood flow in 23 patients with Type II diabetes and 21 control subjects, matched for age, sex, blood pressure, body mass index, weight and smoking habits. Serotonin as a stimulator of nitric oxide-dependent vasodila- tion and sodium nitroprusside as a stimulator of endothelium-independent vasodilation were infused.

Results. Serotonin-induced vasodilation was blunted $(53 \pm 30$ vs $102 \pm 66 \mathrm{M} / \mathrm{C} \%, p<0.005)$ and nitroprussideinduced vasodilation was mildly reduced $(275 \pm 146$ vs $391 \pm 203 \mathrm{M} / \mathrm{C} \%, p<0.05)$ in patients with Type II diabetes compared to control subjects. 5-MTHF improved nitric oxide-mediated vasodilation (from $53 \pm 30$ to $88 \pm 59 \mathrm{M} / \mathrm{C} \%, p<0.05)$ in patients with Type II diabetes mellitus. As expected, 5-MTHF had no effect on forearm blood flow in control subjects.

Conclusion/interpretation. These data imply that folate can be used to improve nitric oxide status and to restore endothelial dysfunction in patients with Type II diabetes. Our results provide a strong rationale for the initiation of studies that investigate whether supplementation with folic acid prevents future cardiovascular events in this patient group. [Diabetologia (2002) 45:1004-1010]

Keywords Nitric oxide, plethysmography, vasomotion, Type II diabetes mellitus, folate.
Type II (non-insulin-dependent) diabetes mellitus is characterised by early development of atherosclerosis

Received: 24 January 2002 / Revised: 25 March 2002

Published online: 6 June 2002

(C) Springer-Verlag 2002

Corresponding author: Dr. T. J. Rabelink, Department of Vascular Medicine and Diabetes, Room No. F02.124, University Medical Center, Utrecht, Heidelberglaan 100, 3584 CX, Utrecht, The Netherlands, E-mail: t.rabelink@azu.nl Abbreviations: NO, Nitric oxide; eNOS, endothelial nitric oxide synthase; FBF, forearm blood flow; 5-MTHF, 5-methyltetrahydrofolate; $\mathrm{BH}_{4}$ tetrahydrobiopterin. resulting in high morbidity and mortality. Aggressive management of cardiovascular risk factors such as hypertension and dyslipidaemia has been shown to prevent cardiovascular and other long-term complications in diabetic patients $[1,2,3]$. Nevertheless, diabetes-related cardiovascular mortality is increasing while risk factor management in diabetic patients is notoriously difficult [4].

It is clear that additional strategies that reduce atherosclerosis and vascular injury in diabetic patients will be of great clinical importance. Particularly if these strategies are safe and easily applicable. 
The endothelium, and in particular endotheliumderived nitric oxide (NO) has emerged as a first line defence mechanism against atherosclerosis. It has been shown that impaired NO-dependent vasodilation predicts the outcome in cardiovascular compromised patient groups [5, 6, 7]. In diabetes, impaired NO availability has been shown $[8,9,10,11,12]$ and could be related to the common risk factors, such as hypertension and dyslipidemia. Hyperglycaemia itself could have direct effects on NO availability. High glucose has been shown to increase oxygen radical formation in endothelial cells [13] which causes enhanced NO degradation. The NO-producing enzyme, endothelial NO-synthase (eNOS), 'uncouples' under hyperglycaemic conditions; i.e. eNOS produces superoxide rather than NO [13]. Oxidative modification of the NOS co-factor tetrahydrobiopterin $\left(\mathrm{BH}_{4}\right)$ is probably the key in this phenomenon [14]. Indeed, in vivo, $\mathrm{BH}_{4}$ supplementation has been shown to restore eNOS function and reduce vascular oxidative stress in insulin-resistant rats [15].

Of interest, amelioration of eNOS function also can be achieved by using folic acid. The active form of folic acid, 5-methyltetrahydrofolate (5-MTHF), restores the function of uncoupled eNOS. Although the exact mechanism by which 5-MTHF acts is not known, it is clear that its effects are $\mathrm{BH}_{4}$-dependent [16]. Endothelial cells produce twofold more NO in the presence of folate [16].

Both intra-arterial administration of 5-MTHF as well as oral supplementation of folic acid restore endothelial function in patients with familial hypercholesterolaemia $[17,18]$. The beneficial effects encountered in hypercholesterolaemic patients do not necessarily predict similar effects in diabetic patients. In our study we investigated whether folate could also restore NO availability in vivo in Type II diabetic patients. If folate is capable of restoring the endothelial dysfunction, commonly encountered in diabetic patients, this could have important clinical implications because endothelial dysfunction is associated with increased cardiovascular risk.

\section{Subjects and methods}

Subjects. We recruited 25 patients with Type II diabetes mellitus and 21 control subjects, matched for age, sex, BMI, weight, smoking habits and blood pressure. Two patients with Type II diabetes were withdrawn from the study before the start of the vascular assessments (one because of technical difficulties due to cannulation of the brachial artery and one patient was lost during follow-up). A total of 23 patients with Type II diabetes and 21 control subjects completed the study. The median duration of diabetes was 8 years (range 1-to-24 years). Diabetes was treated by insulin in eleven patients, by oral hypoglycaemic drugs in eight patients and by both insulin and oral hypoglycaemic drugs in four patients. None of the patients or control subjects had evidence of clinical macrovascular disease or macroalbuminuria. Only four patients with diabetes had microalbuminuria, assessed by a qualitative method (ComburTest, Roche, Mannheim, Germany). Studies were carried out at least 4 weeks after withdrawal of confounding vasoactive medication such as lipid lowering medication, angiotensin converting enzyme inhibitors, angiotensin receptor blockers, nitrates, calcium channel blockers, estrogens, non-steroidal anti inflammatory drugs (NSAID's) and vitamin supplementation. Insulin-treated patients did not receive insulin on the morning of and during the vascular assessments.

This study was designed as an open-label study. Subjects served as their own control. The study was not placebo controlled.

All subjects gave written informed consent and the local research ethics committee of the University Medical Center Utrecht approved the protocol. All studies were carried out in accordance with local institutional guidelines in our GCPcertified unit.

Forearm plethysmography. All subjects refrained from alcohol, tobacco and drinks containing caffeine and fasted for at least 12 hours before the measurements were done. Measurements were done in a quiet room with a constant normal temperature $\left(22-24^{\circ} \mathrm{C}\right)$. Forearm blood flow (FBF) was measured in both arms by venous occlusion mercury strain gauge plethysmography (Hokanson EC-4, Bellevue, Wash., USA) [17, 18, 19, 20, 21]. In previous experiments from our group with patients with Type II diabetes the variance was 0.45 , using the same plethysmography system. A microcomputer based, R-wave triggered system for online monitoring was used. Upper-arm cuffs were inflated automatically to $40 \mathrm{mmHg}$ during four heartbeats, four times a minute during the last 3 min of every measurement. Wrist cuffs were inflated to $200 \mathrm{mmHg}$ or at least $40 \mathrm{mmHg}$ above systolic blood pressure to exclude the hands from the circulation [22]. FBF measurements were recorded during the last 2 to $3 \mathrm{~min}$ of every 5 to 7 -min period of infusion of saline or drug, at $5 \mathrm{~min}$ intervals. The brachial artery of the nondominant arm was cannulated with a 20-gauge flexible, polyurethane catheter (Arrow International, USA). Saline 0.9\% (Baxter Healthcare, Deerfield, Ill., USA) was infused for at least $45 \mathrm{~min}$ before intra arterial administration of vasoactive drugs. All drugs were administered at a constant infusion rate of $90 \mathrm{ml} / \mathrm{h}$. Serotonin (5-HT, Sigma Chemicals, St. Louis, Mo., USA) was infused into the brachial artery at increasing doses of $0,0.6,1.8,6.0 \mathrm{ng} / 100 \mathrm{ml}$ forearm volume $(\mathrm{FAV}) / \mathrm{min}$. This protocol has previously been shown to cause a dose-dependent increase in endothelium-dependent, NO-mediated vasodilation. We and others have shown that the effect of serotonin can be completely abolished by L-NMMA, a specific inhibitor of NO $[19,20,21,23]$. Acetylcholine, which also can be used to investigate endothelium-dependent vasodilation is less specific as it stimulates both NO and EDHF. Sodium nitroprusside (SNP, Merck, Germany) was infused at increasing doses of 0, 6, 60, 180 and $600 \mathrm{ng} / 100 \mathrm{ml} \mathrm{FAV/min} \mathrm{to} \mathrm{assess} \mathrm{endothelium-}$ independent vasodilation. The order of the infusions was randomised. Measurements with serotonin and sodium nitroprusside were repeated during and after at least $30 \mathrm{~min}$ intra-arterial co-infusion of 5-methyltetrahydrofolate (5 MTHF, AHP Pharma, the Netherlands) at an infusion rate of $1 \mu \mathrm{g} / 100 \mathrm{ml}$ $\mathrm{FAV} / \mathrm{min}$. This protocol has been shown to increase local folate values in the venous effluent of the infused arm from 9.4 to $307 \mathrm{nmol} / \mathrm{l}$ in control subjects and from 9.1 to $240 \mathrm{nmol} / \mathrm{l}$ in patients with familial hypercholesterolaemia. For comparison, oral supplementation of folic acid $(5 \mathrm{mg}$ od) increases folate levels to around $150 \mathrm{nmol} / 1$ [17, 18]. All infusates were prepared in a pharmacy department in accordance with GMP guidelines. 
Statistical analysis. The forearm blood flow (FBF) recordings made in the first $30 \mathrm{~s}$ after wrist cuff inflation were not used for analysis. Average values of the FBF of the measurement (cannulated) and control arm were obtained from the last four to six recordings of each measurement period. The ratio of flow in the infused measurement $(\mathrm{M})$ and non-infused control (C) arm was calculated for each recording (M:C ratio). The average value of the $\mathrm{M}: \mathrm{C}$ ratio was calculated from these four to six $\mathrm{M}: \mathrm{C}$ ratios. This $\mathrm{M}: \mathrm{C}$ ratio provides an internal control by excluding systemic factors from influencing the results [24]. Forearm blood flow data for each vasoactive agent are shown in the text as the mean response $( \pm S D)$ at baseline and during infusion of the highest dose. The results are expressed as $\mathrm{M}: \mathrm{C}$ ratio or percentage change of $\mathrm{M}: \mathrm{C}$ ratio from baseline $\mathrm{M}: \mathrm{C}$ ratio (M:C\%). Differences in forearm reactivity were analysed with paired and unpaired Student's $t$ tests. In case of non-normal distribution the Wilcoxon Signed Rank test or the Mann Whitney U test was used. Group comparisons with respect to unmatched clinical characteristics were made with unpaired and two-tailed Student's $t$ tests. The study was designed to detect an increase of the M:C-ratio of 0.4 of the highest dose of serotonin after folate co-infusion. We needed 20 subjects to show this difference with an alpha of 0.05 (two-sided) and $80 \%$ power based on a standard deviation of 0.6 (M:C ratio) from our previous studies. Statistical significance was taken at the $5 \%$ level.

\section{Results}

Subjects. Clinical characteristics of the subjects are shown in Table 1 . As expected, serum concentration of fasting plasma glucose (FPG) $(p<0.0001)$, glycosylated haemoglobin $\left(\mathrm{HbA}_{1 \mathrm{c}}\right) \quad(p<0.0001)$, total cholesterol $(p<0.05)$, LDL $(p<0.05)$ and triglycerides $(p<0.01)$ were higher in diabetic patients. HDL $(p<0.01)$ was lower in diabetic patients.

Baseline forearm blood flow per se tends to be higher in patients with Type II diabetes compared to the control group but this difference is not significant (3.4 \pm 1.2 vs $2.7 \pm 0.9 \mathrm{ml} / 100 \mathrm{ml} \mathrm{FAV/min}$, respectively, NS). Baseline forearm blood flow expressed as M:C ratio was similar in both groups $(1.2 \pm 0.3$ vs $1.3 \pm 0.5$, respectively).

Serotonin-induced and sodium nitroprusside-induced vasodilation in patients with Type II diabetes and control subjects. Serotonin-induced vasodilation was severely impaired in patients with Type II diabetes compared with control subjects [M:C ratio from $1.2 \pm 0.3$ to $1.8 \pm 0.6$ (increase $53 \pm 30 \mathrm{M}: \mathrm{C} \%$ ) vs $\mathrm{M}: \mathrm{C}$ ratio from $1.3 \pm 0.4$ to $2.5 \pm 0.8$ (increase $102 \pm 66 \mathrm{M}: \mathrm{C} \%$ ) respectively, $p<0.005]$. Nitroprusside-induced vasodilation was also reduced in diabetic patients compared to controls [M:C ratio from $1.2 \pm 0.4$ to $4.3 \pm 2.1$ (increase $275 \pm 146 \mathrm{M}: \mathrm{C} \%$ ) vs $1.3 \pm 0.4$ to $5.9 \pm 2.2$ (increase $391 \pm 203 \mathrm{M}: \mathrm{C} \%$ ) respectively, $p<0.05]$.

Effect of 5-MTHF co-infusion on serotonin-induced and sodium- nitroprusside induced vasodilation in patients with Type II diabetes. 5-MTHF had no effect on the baseline M:C ratio in patients with Type II
Table 1. Clinical characteristics and laboratory data. Values are mean \pm SD or number $(\%)$

\begin{tabular}{lcc}
\hline & $\begin{array}{c}\text { Type II } \\
\text { diabetic } \\
\text { patients }\end{array}$ & $\begin{array}{c}\text { Control } \\
\text { subjects }\end{array}$ \\
& 23 & \\
\hline$n=$ & $58 \pm 8$ & $58 \pm 9$ \\
Age (years) & $8 / 15$ & $7 / 14$ \\
Sex (men/women) & $30.3 \pm 5.1$ & $28.0 \pm 3.8$ \\
BMI (kg/m2) & $84 \pm 14$ & $83 \pm 14$ \\
Weight (kg) & $151 \pm 2$ & $145 \pm 19$ \\
Systolic BP (mmHg) & $90 \pm 8$ & $90 \pm 10$ \\
Diastolic BP (mmHg) & $71 \pm 10$ & $67 \pm 8$ \\
Heart rate (/min) & $6 / 26 \%$ & $4 / 19 \%$ \\
Smokers (n/\%) & $5.8 \pm 1.0^{\mathrm{a}}$ & $4.9 \pm 1.2$ \\
Total cholesterol (mmol/l) & $2.2 \pm 1.2^{\mathrm{b}}$ & $1.3 \pm 0.7$ \\
Triglyceride (mmol/l) & $1.2 \pm 0.3^{\mathrm{b}}$ & $1.5 \pm 0.3$ \\
HDL-cholesterol (mmol/l) & $4.1 \pm 1.1^{\mathrm{a}}$ & $3.2 \pm 0.7$ \\
LDL-cholesterol (mmol/l) & $77 \pm 11$ & $74 \pm 11$ \\
Creatinin (umol/l) & $8.6 \pm 1.3^{\mathrm{c}}$ & $5.8 \pm 0.3$ \\
HbA ${ }_{1 \mathrm{C}}(\%)$ & $8.9 \pm 2.5^{\mathrm{c}}$ & $5.8 \pm 0.3$ \\
Fasting plasma glucose (mmol/l) & $1.2 \pm 0.3$ & $1.3 \pm 0.5$ \\
Baseline M:C ratio & $3.4 \pm 1.2$ & $2.7 \pm 0.9$ \\
Baseline FBF (ml/100 ml FAV/min) & & \\
\hline
\end{tabular}

${ }^{\mathrm{a}} p<0.05 ; \quad{ }^{\mathrm{b}} p<0.01 ; \quad{ }^{\mathrm{c}} p<0.001$

diabetes $(1.2 \pm 0.3$ vs $1.3 \pm 0.4 \mathrm{M}$ :C ratio for saline vs 5-MTHF co-infusion at baseline, NS). The impaired serotonergic response was enhanced during 5-MTHF infusion in patients with Type II diabetes [M:C ratio from $1.2 \pm 0.4$ to $1.8 \pm 0.6$ (increase $53 \pm 30 \mathrm{M}: \mathrm{C} \%$ ) without 5-MTHF co-infusion vs $\mathrm{M}: \mathrm{C}$ ratio from $1.3 \pm 0.4$ to $2.4 \pm 0.8$ (increase $88 \pm 59 \mathrm{M}: \mathrm{C} \%$ ) with 5 -MTHF co-infusion, $p<0.05]$. The difference in serotonin-induced vasodilation between diabetic patients and control subjects was abolished after administration of 5-MTHF [M:C ratio from $1.3 \pm 0.4$ to $2.4 \pm 0.8$ (increase $88 \pm 59 \mathrm{M}: \mathrm{C} \%$ ) vs $\mathrm{M}: \mathrm{C}$ ratio from $1.4 \pm 0.5$ to $2.7 \pm 0.9$ (increase $90 \pm 45 \mathrm{M}: \mathrm{C} \%$ ) respectively, NS] (Fig. 1). In patients with Type II diabetes, 5-MTHF had no effect on nitroprusside-induced vasodilation [M:C ratio from $1.2 \pm 0.4$ to $4.3 \pm 2.1$ (increase $275 \pm$ $146 \mathrm{M}: \mathrm{C} \%$ ) without 5-MTHF co-infusion vs M:C ratio from $1.4 \pm 0.5$ to $4.3 \pm 1.6$ (increase $235 \pm 121 \mathrm{M}$ :C $\%$ ) with 5-MTHF co-infusion, NS] (Fig. 2).

Effect of 5-MTHF co-infusion on serotonin-induced and sodium nitroprusside-induced vasodilation in the control subjects. 5-MTHF had no effect on baseline $\mathrm{M}: \mathrm{C}$ ratio in control subjects $(1.3 \pm 0.5$ vs $1.3 \pm 0.4 \mathrm{M}: \mathrm{C}$ ratio for saline vs saline plus 5-MTHF co-infusion at baseline). 5-MTHF did not affect forearm blood flow responses to serotonin [M:C ratio from $1.3 \pm 0.5$ to $2.5 \pm 0.8$ (increase $102 \pm 66 \mathrm{M}: \mathrm{C} \%$ ) without 5 -MTHF co-infusion vs $\mathrm{M}: \mathrm{C}$ ratio from $1.4 \pm 0.4$ to $2.7 \pm 0.9$ (increase $90 \pm 44 \mathrm{M}: \mathrm{C} \%$ ) with 5-MTHF co-infusion, NS] or nitroprusside in control subjects [M:C ratio from $1.3 \pm 0.4$ to $5.9 \pm 2.2$ (increase $391 \pm 203 \mathrm{M}: \mathrm{C} \%$ ) without 


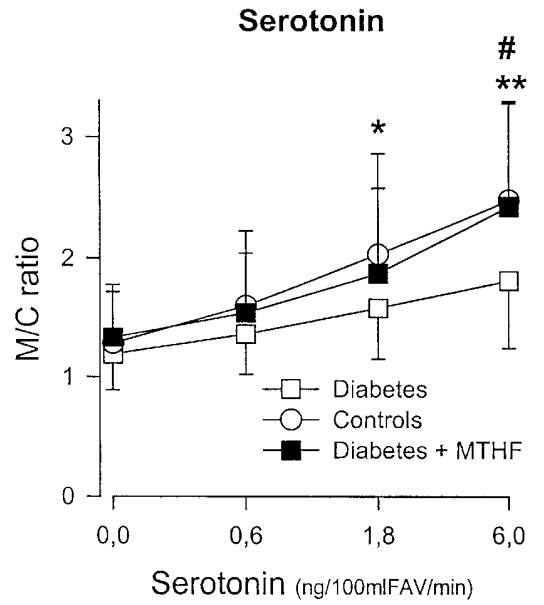

Fig. 1. Change in $\mathrm{M}: \mathrm{C}$ ratio after stimulation of NO-mediated, endothelium-dependent vasodilation with serotonin. NO-dependent vasodilation is impaired in patients with Type II diabetes $(\square)$ compared with matched control subjects $(\bigcirc)(* p<0.01$, $* * p<0.005)$. 5-MTHF normalised NO-mediated vasodilation in patients with Type II diabetes $(\mathbf{\square})(\# p<0.05)$

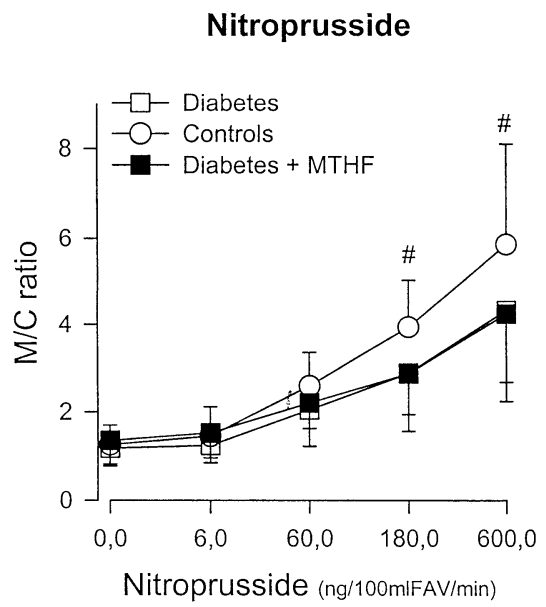

Fig. 2. Change in $\mathrm{M}: \mathrm{C}$ ratio after stimulation of endotheliumindependent vasodilation by sodium nitroprusside. Endotheliumindependent vasodilation is modestly reduced in patients with Type II diabetes $(\square)$ compared with matched control subjects (O). (\#p<0.05). 5-MTHF has no effect on endothelium-independent vasodilation in patients with Type II diabetes (

5-MTHF co-infusion versus M:C ratio from $1.3 \pm 0.4$ to $5.3 \pm 2.0$ (increase $333 \pm 219 \mathrm{M}: \mathrm{C} \%$ ) with 5 -MTHF co-infusion, NS].

\section{Discussion}

The main feature of this study is that, in patients with Type II diabetes, administration of 5-MTHF, the active form of folic acid, restores endothelial dysfunction as measured by serotonin-induced vasodilation. In addition to serotonin-induced vasodilation, also nitroprusside-induced vasodilation was impaired in patients with Type II diabetes. Nitroprusside-induced vasodilation, however, was not affected by 5 -MTHF infusion. These data indicate an important role of 5-MTHF on endogenous NO-availability and could support previous studies suggesting a direct beneficial effect of 5-MTHF on NO-synthase function. This effect occurred despite the presence of mild dyslipidaemia, hypertension and increased glucose concentrations. These factors are all known to affect NO availability. In the context of the increasing evidence that endothelial dysfunction predicts cardiovascular events this finding is relevant for the treatment of patients with diabetes.

Vascular responses at baseline. Baseline forearm blood flow per se was slightly higher in patients with Type II diabetes compared to the control group. This could be due to the osmotic effect of glucose as this phenomenon in the forearm is also seen during hyperglycaemia due to infusion of glucose and during equimolar infusion of mannitol $[25,26]$. Baseline forearm blood flow expressed as $\mathrm{M}: \mathrm{C}$ ratio was similar in both groups.

Most studies evaluating vascular reactivity in patients with Type II diabetes have observed impaired endothelium-dependent responses in forearm blood vessels $[8,9,10,11]$. We show an impaired serotonin-induced vasodilation in forearm resistance arteries in patients with Type II diabetes. Serotonin responses can be completely blocked by NO-inhibition [19, 20, 21, 23] strongly suggesting a specific defect in endothelial NO release in these diabetic patients.

Type II diabetic patients are almost inevitably characterised by the presence of concomitant cardiovascular risk factors such as hypertension, dyslipidaemia and overweight, which can negatively affect vascular responses. The diabetic patients studied are representative for the general Type II diabetic population. The simultaneous assessment of a control group, matched for age, sex, weight, smoking habits and blood pressure allows exclusion of these matched conventional risk factors as major cause for the difference between diabetic patients and control subjects in this study. As expected, a difference could be shown between total-, LDL- and HDL-cholesterol and triglycerides from diabetic patients and control subjects. The degree of diabetes-related dyslipidaemia was mild with a disproportionally severe impairment in NO-mediated dilatation. In comparison, in studies from our laboratory in severely dyslipidaemic patients with familial hyperlipidaemias, the disturbance in NO-mediated vasodilation was milder than the disturbance in the currently studied diabetic group $[17,18,19]$. This implies that specific diabetes-related factors are largely responsible for the impaired NO-dependent responses in these patients.

In the study group of Type II diabetic patients we also observed a mild impairment of the endotheliumindependent response. This has also been shown by 
others $[9,10]$. However, whereas decreased responsiveness of the smooth muscle cells to NO and/or enhanced generation of endothelium-derived constricting factors $[27,28]$ might have contributed to the impaired endothelium-dependent NO-mediated vasodilator response, this data suggests a vital defect in endothelium-derived NO bioavailability in patients with Type II diabetes.

Effect of 5-MTHF administration on forearm vasomotion. We showed that 5-MTHF administration restores impaired NO-mediated vasodilation in patients with Type II diabetes despite the presence of several diabetes-related risk factors such as hyperglycaemia, dyslipidaemia and hypertension. Impaired NO availability in diabetes could be the result of increased degradation of NO by oxygen radicals or the result of decreased formation of NO. With regard to increased breakdown of NO, several mechanisms have been suggested to contribute to increased oxygen radical formation in diabetes [29]. Advanced glycation end products could induce radical formation directly as well as indirectly by activating their cellular receptors (RAGE) [30, 31, 32]. In addition, hyperglycaemia leads to activation of protein kinase $\mathrm{C}$ $[33,34]$, which has also been shown to result in the induction of oxygen radical stress [35]. Activation of the polyol pathway by hyperglycaemia and glucoseauto oxidation are able to induce oxygen radical stress [36, 37]. Increased formation of superoxide (O2-) and the subsequent reaction with NO results in the formation of the highly cytotoxic peroxynitrite (ONOO-) [38].

Oxidative stress has been shown to induce oxidation of $\mathrm{BH}_{4}$ [14] and subsequently contributes to eNOS uncoupling, i.e. reduced NO production and increased eNOS-derived superoxide production $[39,40,41]$. Indeed $\mathrm{BH}_{4}$ supplementation has been shown to improve endothelial function in in vivo conditions characterised by increased oxidative stress such as human hypercholesterolaemia [42], coronary artery disease [43] and experimental diabetes [44].

Recently, we were able to show that, on a molecular level, administration of 5-MTHF, the active form of the pterin folic acid, restores the function of 'uncoupled' eNOS in a $\mathrm{BH}_{4}$-dependent manner [16]. The exact mechanism is not known. 5-MTHF is a 20-fold less effective anti-oxidant compared to the well known anti-oxidant vitamin $\mathrm{C}$. It has been suggested that folate acts as a facilitator of the effect of $\mathrm{BH}_{4}$ on electron flux of NOS [16]. Our study is in line with this pathophysiological concept as we observe an effect of 5-MTHF administration on endothelium-dependent, NO-mediated vasodilation in Type II diabetes. The ameliorative effect of 5-MTHF seems to be specific for endothelium-derived NO, because an improvement could not be observed for endothelium-independent NO-mediated vasodilation.

Several studies have shown that folic acid treatment reduces homocysteine concentrations [45, 46]. Patients with hyperhomocysteinaemia have endothelial dysfunction which can be improved by folic acid $[47,48]$. We have previously shown in patients with familial hypercholesterolemia that acute administration of 5-MTHF in the forearm vasculature increased folic acid concentrations and improves endothelial function without affecting homocysteine concentrations [18]. Although we cannot exclude the possibility of an effect of folate on homocysteine concentrations based upon these earlier results this effect is not likely in our study.

We show a specific ameliorative effect of the active form of folic acid, 5-MTHF, on endothelial dysfunction as measured by endothelium-dependent NO-mediated vasodilation in patients with uncomplicated Type II diabetes. This could be of clinical importance since endothelial dysfunction is associated with increased cardiovascular risk. Our results provide a strong rationale for the initiation of studies that investigate whether in this patient group supplementation with folic acid, a safe, readily available, not expensive and well-tolerated drug, prevents future cardiovascular events.

Acknowledgements. We acknowledge Jos Op't Roodt for his excellent technical assistance and the Kendle Pharmacology Unit Utrecht for their support.

\section{References}

1. UK Prospective Diabetes Study Group (1998) Tight blood pressure control and risk of macrovascular and microvascular complications in type 2 diabetes. BMJ 317:703-713

2. Kreisberg RA (1998) Diabetic dyslipidemia. Am J Cardiol 82:67U-73U

3. Pyorala K, Pedersen TR, Kjekshus J, Faergeman O, Olsson AG, Thorgeirsson G (1997) Cholesterol lowering with simvastatin improves prognosis of diabetic patients with coronary heart disease. A subgroup analysis of the Scandinavian Simvastatin Survival Study (4S). Diabetes Care 20:614-620

4. Olefsky JM (2000) Prospects for research in diabetes mellitus. JAMA 285:628-632

5. Neunteufl T, Heher S, Katzenschlager R et al. (2000) Late prognostic value of flow-mediated dilation in the brachial artery of patients with chest pain. Am J Cardiol 86:207210

6. Suwaidi JA, Hamasaki S, Higano ST, Nishimura RA, Holmes DR, Lerman A (2000) Long term follow up in patients with mild coronary artery disease and endothelial dysfunction. Circulation 101:948-954

7. Schachinger V, Britten MB, Zeiher AM (2000) Prognostic impact of coronary vasodilator dysfunction on adverse long-term outcome of coronary heart disease. Circulation 101:1899-1906 
8. Gazis A, White DJ, Page SR, Cockroft JR (1999) Effect of oral vitamin $\mathrm{E}$ ( $\alpha$-tocopherol) supplementation on vascular endothelial function in type 2 diabetes mellitus. Diabet Med 16:304-311

9. McVeigh GE, Brennan GM, Johnstone GD et al. (1992) Impaired endothelium-dependent and independent vasodilation in patients with Type II (non-insulin-dependent) diabetes mellitus. Diabetologia 35:771-776

10. Williams SB, Cusco JA, Roddy M, Johnstone MT, Creager MA (1996) Impaired nitric oxide mediated vasodilation in patients with non-insulin-dependent diabetes mellitus. J Am Coll Cardiol 27:567-574

11. Ting HH, Timimi FK, Boles KS, Creager SJ, Ganz P, Creager MA (1996) Vitamin C improves endotheliumdependent vasodilation in patients with non-insulin-dependent diabetes mellitus. J Clin Invest 97:22-28

12. Nitenberg A, Valensi P, Sachs R, Dali M, Aptecar E, Attali J (1993) Impairment of coronary vascular reserve and Ach-induced coronary vasodilation in diabetic patients with angiographically normal coronary arteries and normal left ventricular systolic function. Diabetes 42:1017-1025

13. Cosentino F, Hishikawa K, Katusic ZS, Luscher TF (1997) High glucose increases nitric oxide synthase expression and superoxide anion generation in human aortic endothelial cells. Circulation 96:25-28

14. Milstien S, Katusic Z (1999) Oxidation of tetrahydrobiopterin by peroxynitrite: implications for vascular endothelial dysfunction. Biochem Biophys Res Commun 263:681-684

15. Shinozaki K, Nishio Y, Okamura T et al. (2000) Oral supplementation of tetrahydrobiopterin prevents endothelial dysfunction and vascular oxidative stress in the aortas of insulin resistant rats. Circ Res 87:566-573

16. Stroes ESG, van Faassen EE, Martasek P et al. (2000) Folic acid reverts dysfunction of endothelial nitric oxide synthase. Circ Res 86:1129-1134

17. Verhaar MC, Wever RMF, Kastelein JJP et al. (1999) Effects of oral folic acid supplementation on endothelial function in familial hypercholesterolemia. A randomised placebo-controlled trial. Circulation 100:335-338

18. Verhaar MC, Wever RMF, Kastelein JJP, Dam T van, Koomans HA, Rabelink TJ (1998) 5-Methyltetrahydrofolate, the active form of folic acid, improves endothelial function in familial hypercholesterolemia. Circulation 97:237-241

19. Stroes ESG, Koomans HA, Bruin TWA de, Rabelink TJ (1995) Vascular function in the forearm of hypercholesterolaemic patients off and on lipid-lowering medication. Lancet 346:467-471

20. Honing MLH, Smits P, Morrison PJ, Rabelink TJ (2000) Bradykinin induced vasodilation of human forearm resistance vessels is primarily mediated by endothelium-dependent hyperpolarization. Hypertension 35:1314-1318

21. Verhaar MC, Honing ML, van-Dam T et al. (1999) Nifedipine improves endothelial function in hypercholesterolemia, independently of an effect on blood pressure or plasma lipids. Cardiovasc Res 42:752-760

22. Lenders J, Janssen G-J, Smits P, Thien T (1991) Role of the wrist cuff in forearm plethysmography. Clin Sci (Colch) 80:413-417

23. Bruning TA, Chang PC, Blauw GJ, Vermeij P, Zwieten PA van (1993) Serotonin-induced vasodilation in the human forearm is mediated by the 'nitric oxide pathway': no evidence for involvement of the 5-HT3-receptor. J Cardiovasc Pharmacol 22:44-51

24. Benjamin N, Calver A, Collier J, Robinson B, Vallance P, Webb D (1995) Measuring forearm blood flow and interpreting the responses to drugs and mediators. Hypertension 25:918-923
25. Williams SB, Goldfine AB, Timimi FK et al. (1998) Acute hyperglycemia attenuates endothelium-dependent vasodilation in humans in vivo. Circulation 97:1695-1701

26. De Koning E, Etten RW van, Gaillard C, Rabelink T (2001) Rapid impairment of endothelial function by hyperglycemia: restoration by vitamin C. Diabetes 50:A151 (Abstract)

27. Cockroft JR, Chowienczyk PJ, Brett SE, Ritter JM (1994) Effect of NG-monomethyl-L-arginine on kinin-induced vasodilation in the human forearm. Br J Clin Pharmacol 38:307-310

28. O'Kane KP, Webb DJ, Collier JG, Vallance PJ (1994) Local L-NG-monomethyl-arginine attanuates the vasodilator action of bradykinin in the human forearm. Br J Clin Pharmacol 38:311-315

29. De Vriese AS, Verbeuren TJ, Van de Voorde J, Lameire NH, Vanhoutte PM (2000) Endothelial dysfunction in diabetes. Br J Pharmacol 130:963-974

30. Bucala R, Tracey KJ, Cerami A (1991) Advanced glycosylation end products quench nitric oxide and mediate defective endothelium-dependent vasodilation in experimental diabetes. J Clin Invest 87:432-438

31. Ceriello A (1999) Hyperglycemia: the bridge between nonenzymatic glycation and oxidative stress in the pathogenesis of diabetic complications. Diabetes Nutr Metab 12:4246

32. Yan SD, Schmidt AM, Anderson GM et al. (1994) Enhanced cellular oxidant stress by the interaction of advanced glycation end products with their receptors/ binding proteins. J Cell Biol 269:9889-9897

33. Craven PA, Studer RK, Negrete H, Derubertis FR (1995) Protein kinase $\mathrm{C}$ in diabetic nephropathy. J Diabetes Complications 9:241-245

34. Tesfamariam B, Brown ML, Cohen RA (1991) Elevated glucose impairs endothelium dependent relaxation by activating protein kinase C. J Clin Invest 87:16431648

35. Ohara Y, Peterson TE, Zheng B, Kuo JF, Harrison DG (1994) Lysophosphatidylcholine increases vascular superoxide anion production via protein kinase $\mathrm{C}$ activation. Arterioscler Thromb 14:1007-1013

36. Giugliano D, Ceriello A, Paolisso G (1996) Oxidative stress and diabetic vascular complications. Diabetes Care 19:257-267

37. Wolff SP, Dean RT (1987) Glucose autoxidation and protein modification. The potential role of oxidative glycosylation in diabetes. Biochem J 245:243-250

38. Wever R, Stroes E, Rabelink T (1998) Nitric oxide and hypercholesterolemia: a matter of oxidation and reduction? Atherosclerosis 137:S51-S60

39. Stroes E, Hijmering M, Zandvoort $M$ van, Wever R, Rabelink TJ, Faassen EE van (1998) Origin of superoxide production by endothelial nitric oxide synthase. FEBS Lett 438:161-164

40. Vasquez-Vivar J, Kalyanaraman B, Martasek $\mathrm{P}$ et al. (1998) Superoxide generation by endothelial nitric oxide synthase: the influence of cofactors. Proc Natl Acad Sci USA 95:9220-9225

41. Wever RMF, Lüscher TF, Cosentino F, Rabelink TJ (1998) Atherosclerosis and the two faces of endothelial nitric oxide synthase. Circulation 97:108-112

42. Stroes E, Kastelein J, Cosentino F et al. (1999) Tetrahydrobiopterin restores endothelial function in hypercholesterolemia. J Clin Invest 99:41-46

43. Maier W, Cosentino F, Lutolf RB et al. (2000) Tetrahydrobiopterin improves endothelial function in patients with coronary artery disease. J Cardiovasc Pharmacol 35:173-178 
44. Meininger CJ, Marison RS, Hatakeyama K et al. (2000) Impaired nitric oxide production in coronary endothelial cells of the spontaneously diabetic rat is due to tetrahydrobiopterin deficiency. Biochem J 349:353-356

45. Brouwer IA, Dusseldorp M van, West CE et al. (1999) Dietary folate from vegetables and citrus fruit decreases plasma homocysteine concentrations in humans in a dietary controlled trial. J Nutr 126:1135-1139

46. Collaboration HLT (1998) Lowering blood homocysteine with folic acid based supplements: meta-analysis of randomised trials. BMJ 316:894-898
47. Bellamy MF, McDowell IFW, Ramsey MW, Brownlee M, Newcombe RG, Lewis MJ (1999) Oral folate enhances endothelial function in hyperhomocysteinaemic subjects. Eur J Clin Invest 29:659-662

48. Woo KS, Chook P, Lolin YI, Sanderson JE, Metreweli C, Celermajer DS (1999) Folic acid improves arterial endothelial function in adults with hyperhomocysteinemia. J Am Coll Cardiol 34:2002-2006 